\title{
Endemism Versus Dispersion: Contribution of Microbial Genetics for Forensic Evidences
}

\author{
Ricardo Araujo* \\ IPATIMUP, Institute of Pathology and Molecular Immunology, University of Porto, Portugal
}

\begin{abstract}
The characterization, analysis and validation of evidence that concludes the description of an intentional act of biocrime or bioterrorism represent the main target of microbial forensics. But, even nowadays with the most recent technical advances, it remains extremely difficult, labour-demanding and time consuming to investigate and confirm the origin of microbial strains and to identify the person or motif behind the crimes. The true extent of microbial diversity in indoor or outdoor environments may still be underestimated, but its origin and maintenance is starting now to be better understood. Biogeographic patterns and proves of endemism had been occasionally described for few bacterial communities, as well as for fungal populations. Other researchers sustain that microbes are simply so abundant that dispersion and migration capacities support a probable global distribution. Additionally, they possess a remarkable tolerance and adaptation abilities to the most unfavourable environmental conditions. Human body represents other sort of microbial community different from soil and water communities that may be ruled by other variables, particularly the individual genetic background. Nowadays, there is no doubt that molecular markers are important for microbe discriminating and, thus, genotyping methodologies are increasing interest for forensic sciences. The advent of large-scale genotyping studies on microbial populations may provide a unique opportunity to compare genetic diversity within and among populations. The present mini-review focus the most recent developments regarding microbial genetics and population diversity, both community richness and genotype diversity, and its application for criminal cases and forensic evidence.
\end{abstract}

Keywords: Biogeography, crime evidence, metagenome, microbial forensics, microbial diversity, speciation.

\section{INTRODUCTION}

The characterization, analysis and validation of evidence that concludes the description of an intentional act of biocrime or bioterrorism represent the main target of microbial forensics. Numerous cases of use and release of microbial agents as bioweapons have been employed for centuries in order to commit murder or injury against other people [1]. Most of these criminal cases resulted from the simple and easy access by the perpetuator to specific microbial agents with high infectious potential. However, even nowadays with the most recent technical advances, it remains extremely difficult, labour-demanding and time consuming to investigate and confirm strain origin and to identify the person and/or the motifs behind such crime. An example of this vast investigation is being conducted since 2001 and followed the anthrax attacks in USA. The availability of whole genome sequence of several Bacillus anthracis strains and the characterization of some genetic polymorphisms - variable number tandem repeats (VNTRs) and single nucleotide polymorphisms (SNPs) [2, 3] - led to some advances on the investigation of the probable origin of the bacterial spores but several other questions remain to be answered [4]. The systematic review of other criminal cases show repeatedly how difficult is to attest the strain origin or verify intentionality based on epidemiological and molecular data given by research labs and criminal experts. A microbial forensic

*Address correspondence to this author at the IPATIMUP, Institute of Pathology and Molecular Immunology, University of Porto, Rua Dr. Roberto Frias, s/n, 4200-465 Porto, Portugal; Tel: +351 225577700 /

Fax: +351225577709 / E-mail: ricjparaujo@yahoo.com investigation encompasses many resources that include both conventional (such as hair, DNA, documents) and diverse microbiological features [5].

Microbial community profiling and characterization is an important issue for microbial forensics. Biogeographic patterns had been occasionally described for bacterial communities, as well as for fungal populations. Microbial genomes have been widely studied and new terms, like metagenome or pan-genome, became increasingly common in the literature [6]. In fact, genomic technologies brought considerable advances to microbiology, allowing the detailed analysis of populations and complex microbial environments, as well as the comparison of multiple genomes. Airborne metagenome studies performed in indoor environments showed an extensive number of new bacterial and fungal phylotypes, but the overall microbial diversity of airborne samples may even be far below the estimated diversity for soil and water samples [7]. Thus, microbial diversity origin and maintenance is starting now to be better understood. Microbial biogeography is still in its infancy and great prospects are expected during the coming years. The advent of large-scale genotyping studies on microbial populations may provide a unique opportunity to compare genetic diversity within and among populations. The present mini-review focus the most recent developments regarding microbial genetics and population diversity, both community richness and genotype diversity, and its application for criminal cases and forensic evidence.

\section{MICROBIAL METAGENOMICS}

There is a classic assumption of Lourens Baas Becking in microbial ecology about microbial distribution, "everything is everywhere - the environment selects" [8]. This assump- 
tion has been questionable by many researchers, now more than ever. The most recent molecular techniques have revealed extensive microbial diversity but it remains highly controversial among researchers if the current improvements are sufficient to understand microbial communities. In this topic, it will be discussed the factors that may influence microbial metagenomics and the genetic richness of microbial communities.

Microbial metagenomics try to assess and comprehend microbial communities that comprise cultivable and uncultivable organisms. Cultivable microorganisms are easier to quantify by using traditional methods, such as colony forming units (CFU). The uncultivable microorganisms that are present in communities at high density are now detected and quantified by molecular techniques, particularly quantitative PCR. But the detection of rare taxa on microbial communities still remains critical for the global understanding of the value and importance of each microbial taxa. It is known that rare organisms can become collectively relevant and affect important biogeochemical processes, as is the case of some marine bacteria that may at times cumulatively fix more nitrogen than the larger organisms [9]. For many authors, the rare taxa are essential for an accurately description and conception of microbial assemblages, assuring that fingerprinting techniques, such as Terminal Restriction Fragment Length Polymorphism (TRFLP) or Automated Ribosomal Intergenic Spacer Analysis (ARISA), do not reflect the definite microbial diversity. According to them, these methods identify only the dominant members of the community [10]. ARISA for example, represents a high-resolution, greatly reproducible technique for distinguishing fungal communities that uses variability in the length of the intervening transcribed spacer regions of rRNA genes (ITS) to separate several samples into operational taxonomic units (OTUs) [11]. Meanwhile, both electrophoretic methods, TRFLP and ARISA, have been largely employed worldwide for measuring bacterial and fungal species richness. According to their supporters, it can in fact elucidate about the importance of undescribed features of natural prokaryotic assemblages in the fields of ecology, biogeography, and microbiology [10]. Let's discuss this controversy by reviewing what we know about microbial communities.

Microbial communities might be more structured than communities of macroorganisms, as they represent naturally complex ecosystems [8]. The diversity into any community is largely influenced by its size, ecosystem distribution, interactions with other communities or bacterial groups, the community structure, the nature of the environment and nutrient availability [5, 12]. The classical assumption "everything is everywhere" alludes to the remarkable dispersion ability of microorganisms by wind, water and animals. Additionally, other biotic and abiotic gradients, such as disturbance, productivity, area, latitude, and resource heterogeneity may also alter microbial diversity [8]. It is not possible to quantify the importance of each fact for microbial diversity, but it is almost consensual that these factors influence significantly the composition of any microbial community. A large number of rare species are found in most ecosystems, which may in fact result from adaptation to local conditions. Microbial communities seem to be largely influenced by several variables, so communities may change rapidly its composition over space and time. It was suggested, based on studies of morphologically defined protistan species, that in species comprising organisms smaller than $1 \mathrm{~mm}$, the global diversity is relatively low and the organisms are cosmopolitan, lacking any kind of biogeographical variation [13]. The obvious explanation is that microbes are simply so abundant that continuous large-scale dispersion support their global distribution. In this report, Finlay [13] also sustained that microbial eukaryotes are most probably dispersed by random forces that effectively mean a random spatial distribution of microbial eukaryotes. In fact, few analyses of recombination rates in the natural environment have indicated very high migration rates. A case was described in Florida: in 1978, sugarcane rust appeared in America brought by transoceanic wind transport of urediospores of Puccinia melanocephala from the Cameroons to the Dominican Republic in the Caribbean [14]. Finlay' statement remains until now impossible to refute considering the actual technical limitations for identification of all rare taxa. Microbial accumulation curves are commonly reported linear or close to linear because of the high diversity and/or limitations regarding sample size [15]. Presently we can assume that microbes can be so diverse in a community that it is impossible to count them exhaustively. Microbial dispersion theory is also supported by epidemic data from geographic regions far away from any source of inoculum and its association with tropical weather disturbances [14]. For a successful colonization, immigrant spores must germinate and establish successful populations through reproduction and, it is also true, that certain organisms present a remarkable tolerance and adaptation ability to unfavourable environmental conditions. Both microbial resistance and biome expansion as result of climate change [16] might also explain, at least in part, the success of some microbial species in new biomes.

Yet, other studies report that microorganisms are not cosmopolitan, supporting the existence of some kind of endemism. Beta-diversity represents community composition changes across space (distance) and its value is fundamental to understand the true extent and variability of biodiversity [17]. Beta-diversity studies added that microbes exhibited spatially predictable and aggregated patterns over scales ranging from $1 \mathrm{~m}^{2}$ to $10^{10} \mathrm{~m}^{2}$ [18]. Biogeographical patterns may in fact be discernible and microorganisms present moderate regional distribution and moderate regional diversity. Fuhrman and collaborators [8] studied molecular survey data at several habitats in order to show the extent of organisms that are cosmopolitan or endemic within a given habitat type. Of 582 unique OTUs (organisms with at least $97 \% 16 \mathrm{~S}$ ribosomal RNA similarity belong to the same OTU), the study found $69 \%$ of endemism, $17 \%$ of the OTUs were at two locations, $6 \%$ at three locations, and only $0.4 \%$ at all nine studied locations. The more widespread OTUs were also the most abundant at each location. Fuhrman concluded that abundant organisms in one place are more likely to be detectable and abundant in another places, whereas the rarer taxa could be undetectable in several locations [8]. However, drastic changes in biotic or abiotic factors may turn rare OTUs into more abundant ones at some other place or time.

Climatic zones and regional distribution have been described for cold-adapted bacterial populations [19], thermophilic cyanobacteria [20] and hyperthermophilic acidophil Sulfolobus populations [21]. In those cases, geographical 
isolation may be the driving force behind population divergence by limiting the gene flow between distant populations $[20,21]$. Genetically isolated populations may comprise increased ability for local adaptation due to highly stressful environmental conditions. In the other side are the microbial communities setting the greater species richness. These communities are usually located at low latitudes and join higher productivity with higher temperatures - associated to the increase of metabolic rate and speciation processes [8]. Considering other ecosystems, such as marine or fluvial communities, different biogeographic patterns may be detected among microbes as soils present barriers that eventually could not be found in other environments. Marine bacterioplankton communities may be an example of global distribution as they are mixed by ocean currents and exhibit few dominant microbial taxa [22].

And how can microbial diversity be useful for forensic evidence? Few authors already started to investigate microbiology helpfulness in real situations. Heath and collaborators [23] compared the TRF profiles of 3 ecosystems, field, forest and dune, and reported $36.0 \%$ to $55.4 \%$ of intraecosystem, and $23.8 \%$ to $26.3 \%$ of interecosystem similarities, respectively. These results are even more interesting following the coincidental microbial community DNA profile found comparing a soil sample from a site of collection, and a small amount of soil recovered from the sole of a shoe or from dirty clothes [24]. Microbial metagenome profiling using M-TRFLP was also used for characterization and discriminating of several locations in Scotland [25] and USA [26]. In both cases fungal and bacterial communities could provide differentiation between soil types and had a high degree of reproducibility proving to be a potential tool for forensic sciences. The ability of fungal spores to tolerate desiccation may contribute to the stability of metagenomic profile for longer periods of time [25]. As soon as we can define markers for characterization of soil and other samples, bacterial and fungal DNA profiling may provide a practical method for forensic comparison of soil samples without needing additional equipment. Most of the tests can be conducted worldwide in forensic laboratories equipped for human DNA profiling.

Another future topic of interest for microbial forensic researchers and technicians is the value of the data coming from the human microbiome project. This international consortium expects to verify whether humans share a core microbiome, to correlate changes in the human microbiome with changes in human health, and to develop technological and bioinformatic tools necessary for this microbial genetic research (updates considering this project can be found at http://nihroadmap.nih.gov/hmp/ - November 16, 2009). Microbial communities are influenced by and modulate human development, immunity, and nutrition. Future results may considerably explain and change the way we interact with the environment around. Meanwhile, the first results show a high diversity in the salivary microbiome within and between individuals from different continents, but small correlation with geographic distance was found [27]. The description of bacterial communities from diabetes-prone and diabetes-resistant rats showed significantly different results [28]. It seems that any individual collects unique experiences through life and I may guess that in our microbiome is reflected our life style and genetic background. It will not be surprising if in a near future it could be possible to identify and characterize the full microbiome for each person.

It is my opinion that we will not find a single "theory" that can explain the distribution of all microbial communities and species. In fact, different patterns can be seen considering different microbes in similar biomes, or instead, the same microbe under different environmental conditions. One of the biggest challenges nowadays for microbial forensics is to identify which are the microbes useful for forensic evidence and, then, to predict their distribution over space and time in order to increase the confidence of microbial tests available in forensics.

\section{SPECIATION AND MICROVARIATION}

The definition of microbial species has suffered considerable changes over the recent years as consequence of the intense research on microbial genetics. Actually, the "species" definition contains a biological issue, considering a group of individuals or isolates that shares a high degree of genomic similarity, and an ecological concern by including the strains that were studied under the same standardized conditions [29]. At a genomic level, microbial geneticists have defined the "core genome" as the genes responsible for functions of central housekeeping, such as DNA and protein synthesis, and the "flexible genome" includes genes typically encoding accessory functions, such as the transport or use of non-essential nutrients, protection against environmental damage, cell-surface modifications, and many genes with unknown function [8]. Both "core" and "flexible" genomes form the pan-genome for microbial species. All these definitions are important for the studies concerning microbial genetics because microbes can easily interact and transfer genes among them [30]. Conversely to higher eukaryotes that shows high genetic similarity within species, the microbes keep a large part of the genome "flexible" and the core genome tend to be more reduced. Thus, finding a microbial taxa does not necessarily mean that a particular gene will be found, and vice-versa - part of the microbial genome is associated with the specific niche where the organism is living. Thus, it is expected to find large differences between individuals belonging to the same microbial species but living at different biomes or at different time scales. But, how do intra-species variations happen?

Microbes primarily reproduce asexually and, therefore, are clonal in the environment. Universally, organisms tend to evolve and new genotypes appear constantly. Most mutations are likely to be deleterious and in general the mutation rate is likely to be very low. Occasionally, a rise of originated mutators may happen, as described with populations of $E$. coli undergoing long-term adaptation to new environment [31]. Pathogens present a high capacity for breaking down resistance genes and the microbes with additional ability for environmental adaptation usually show mixed reproduction system, high potential for genotype flow, larger population sizes, and/or high mutation rates [30]. Genetic flexibility may somehow represent an advantage for microbes. In natural habitats, microbial populations live under nutritional deficiencies and the growth is very limited because essential nutrients are usually consumed much faster than they become available. High mutation rates can be deadly for some microorganisms but for sure it plays an important role fighting 
against dead and, ultimately, against local extinction by accelerating adaptation and evolving pathogenicity [32]. Some alleles are selected by competitive advantage in stressful environments and particular populations can express advantageous mutations under intense selective pressure [33]. Genotype endemism might be very frequent and a consequence of adaptation for each site or region, as described $[34,35]$. As seen in the previous topic, different microbial species may present different habitat ranges, but even into the same microbial species it is possible to find different genotypes and some of them may be well-adapted than others and the habit range be also higher for the ones more fitted. Reno and collaborators [36] have recently studied the pan-genome of Sulfolobus islandicus demonstrating a biogeographical structure at the genomic level.

The genomic regions that are usually more associated to genetic variation are the tandem repeats, which are adjacent DNA sequences of 2 to 200 nucleotides in length, repeated in sequence identically or partially $[37,38]$. Most repeats are from non-coding regions and, even now, their genomic impact is not completely understood. These regions are typically good for genotyping microbial eukaryotic species because are usually associated to high mutation rates and microvariation $[39,40]$. However, some other repeats are found in coding sequences generating variability in several microbes and particularly changing some phenotypes by increasing their pathogenic potential, such as changing the morphology of cell-surface antigens and adhesins [41]. Genes codifying proteins destined for transport to the plasma membrane or related to secretion are also commonly altered by tandem repeats [42]. Tandem repeats were used to describe the absence of pathogenic ecotypes or biogeography on isolates of Beauveria bassiana [43].

Speciation and microevolution can also be a useful tool for forensic sciences. Mutations occur constantly and may link samples to specific places. Mutation rates in coding or non-coding genomic regions become the driving force for microbial diversity and might be used for forensic determinations. "Close-related strains" and "near matches" are highly problematic in a court, particularly when scientists try to explain relatedness to a people from other subject areas than life sciences. "The doubt can be always there!" A statistical approach with confidence intervals based on population genetic analysis facilitates scientific validation and the jury's evaluation [44]. The combination of multiple approaches may also solve limitations of each single methodology. Geolocation through stable isotope ratios has been used to trace the origins of illicit drugs, to determine the authenticity of plant-derived food products, to map the origin of animal food products and water sources) [45]. This technology have been also suggested for microbial trace and showed to be very useful for association to a specific laboratory [46]. Combined with other microbial genetic tools, the use of isotope ratios could offer relevant forensic information for the location of a particular sample establishing microbe signatures with the culturing conditions.

\section{CASES AND EVIDENCES}

Culture methods present considerable limitations in order to get the complete description of microbial communities living in specific ecotypes, particularly when comparing to genetic techniques that revealed an extensive microbial diversity previously unknown. However, a considerable number of pathogens can still be grown from a single cell and multiplication through culturing and dispersion can be carried out easily without sophisticated technology [47]. Few organisms, such as B. anthracis, are stable in the environment through the production of spores and persist for longer periods even after spread and under unfavourable conditions. Compared with other weapons, microbial dissemination is inexpensive and difficult to detect because residual quantities can be prepared [1]. New genetic assays have been developed in order to verify the origin of microbial strains and general transmission routes for a particular microorganism. Detection of pathogens with increased pathogenicity is crucial and several genomic tools may offer clues for detection of the most dangerous pathogens that sometimes are remarkably similar to the non-pathogenic relatives [1]. Microbiological investigations in forensic sciences are basically similar to other forensic investigations, following the same steps and involving crime scene investigation, evidence collection and storing, analysis of evidence, interpretation of results, and court management. Excellent descriptions of the procedures used for evidence treatment and analysis can be consulted in few previous reviews $[1,48]$. In any case, the first step of such an investigation is the classification of the attack as natural or resulting from an intentional act. A planned attack might be identified by the unlikely occurrence of a disease (atypical season or geography) or unusual illness in people, as well as evidence of genetic engineering or other strain genetic indicator [49]. Microbial genetics was employed in a few reported criminal cases described bellow for clarification of biocrimes, nevertheless it is expected that greater number of forensic investigations will be conducted in near future using genetic microbial data.

One of the first cases that used microbial genetics for forensic investigations happened in 1979. A total of 66 people died of anthrax in Sverdlovsk, Russia [50]. Multiple Loci VNTR Analysis (MLVA) studies demonstrated that 4 different strains of anthrax were present in preserved tissue specimens from the victims. The government informed that people were infected by eating contaminated meat, which was not supported by epidemiologic molecular data. Later on, it was suggested that the disease resulted from inhalational anthrax due to an accidental aerosol emission from a military weapons facility [1].

In 1993, the Aum Shinrikyo cult (that was also responsible for a sarin nerve gas attack in a Tokyo subway) attempted to spread anthrax in Tokyo causing no victims. The MLVA profile of the isolate confirmed that B. anthracis strain was the non-virulent veterinary vaccine strain Sterne [1]. In this case, information regarding strain pathogenicity was sufficient to alert health services and limit the public panic.

By exploring the case of the State of Louisiana vs. Richard J. Schmidt, Budowle \& Harmon [49] reported few limiting, encouraging and challenging topics regarding the close relationship between genetic microbiology and forensic evidence. The criminal case occurred in 1995 and Richard J. Schmidt was accused of second degree attempted murder with a contaminated HIV injection against Janice Trahan [49]. The clinician used blood samples from patients infected 
with HIV and hepatitis C. Sequence data were generated from two genes from HIV isolates and phylogenetic data supported the hypothesis that the HIV variants from the victim (Janice Trahan) and the Dr. Schmidt' patient were closely related [51]. The Court of Appeal of Louisiana believed that was clear evidence that Richard Schmidt had the opportunity to acquire the contaminated HIV blood sample. Portions of the HIV proviral envelope gene from 35 HIVinfected persons living into the same geographic area had also been previously used for molecular prove of HIV transmission by a local dentist [52]. Few questions regarding the methodologies and epidemiological analysis that were raised by the defence experts showed there still remains a large room for improvement in this field, particularly regarding clarity and the elaboration of guidelines for application of microbial genetics on forensics [49]. Anyway, forensic interpretations were admissible of expert testimony. Inclusion of control samples from the source population is essential for molecular epidemiology, as well as the selection of the best genomic region to be used in each study case (time distance between incident and research period should be considered during any investigation) [53].

In Dallas, in 1996, another criminal act involved the use of Shigella dysenteriae type 2 and food contamination affected 12 people of the St. Paul Medical Center hospital. $S$. dysenteriae type 2, recovered from 9 patients' stool samples, from an uneaten muffin, and from the medical laboratory's stock strain were indistinguishable by pulsed-field gel electrophoresis (PFGE) analysis [54]. The criminal investigation focused on a laboratory technician who was later on considered guilty on several felony assaults (intentional infection by pathogenic organism) and falsification of laboratory documents.

One of the most recent bioincidents was the well known anthrax letters attack in 2001 and once again microbial genetics was used for forensic studies. A recent research using MLVA reported that the $B$. anthracis spores from these attacks in the US were the Ames strain. The most probable origin was the Bruce Ivins' laboratory at the U.S. Army Medical Research Institute of Infectious Diseases (USAMRIID), remaining however still to clarify the perpetuator and reasons behind the attack [4]. More detailed attention and intensive research have been conducted since then with $B$. anthracis. A comparison of the whole-genome sequence of B. anthracis isolate from a victim of the bioterrorist anthrax with a reference revealed 60 new markers for genotyping that included SNPs, insertions or deletions, and tandem repeats [3]. Read and collaborators [3] found 11 DNA sequence differences between the chromosomes of the Florida and Porton isolates of B. anthracis that were indistinguishable by their VNTR profiles, and suggested a common ancestor for these isolates in the mid-1980s. A further study in $B$. anthracis whole-genome sequencing revealed 3,500 SNPs among 8 different strains and provided 6 highly specific SNPs for the Ames strain [55]. SNP and VNTR analyses of a collection of $1,033 \mathrm{~B}$. anthracis isolates from 42 countries showed a global population structure that reflected colonialera importation from the Old World into the New World, importation of genotypes into developed countries via sporecontaminated animal products and trade association with introduction of B. anthracis in Australia [56]. All together, these reports show that humans are actively participating in the proliferation and dispersal of anthrax.

Microbial genetics could also clarify the origin of a natural outbreak caused by a strain of the West Nile virus in New York that was isolated from birds and humans. The strain was similar to another strain originally isolated from a dead goose in Israel $[57,58]$. This last report once again clarified the important role of microbial genetics genotyping methods for studying outbreaks, intentional or not.

As seen before, numerous cases exist of intentional use of microbial agents as bioweapons and these situations have been employed in order to commit murder or injury against people. However, microorganisms can also be a useful tool for adding relevant information regarding other crimes. More details will be exposed in the following topic.

\section{OTHER APPLICATIONS OF MICROBIAL GENET- ICS IN FORENSIC SCIENCES}

Microbial agents can easily be used for agriculture biocrimes and, in this case, the detection or prevention can be even more difficult to perform compared to previously seen for spread of human diseases. In USA for example, agriculture and related industries comprise about 1 trillion dollars annually and employ $17 \%$ of the people [59]. The importance of plant disease for forensics was recently reviewed [59]. Nowadays, there is no doubt that molecular markers are important for microbe discriminating and, thus, genotyping methodologies are increasing interest for forensic sciences. Outbreaks, such as the consecutive outbreaks of cyclosporiasis caused by contaminated Guatemalan raspberries in USA and Canada, from 1996 to 1998 [60, 61], alerted to the continuous need of attention to food products coming from foreigner countries and showed how fragile heath and legal systems can be in case of a similar but intentional bioattack.

Forensic sciences also focus their actions on several materials, particularly cadaveric materials, and microbial genetics can also be useful to study these materials. A rapid colonization by local microbial communities happen in cadavers and the communities are replaced over time (or space if the cadaver is moved from one to another location). Microorganisms can also release repellent toxins that sometimes could also be used for a better identification of where a certain crime took place [62]. More research is still necessary about these materials, but there is a large background to be explored by microbial metagenomics in this field.

Presently, there is a growing recognition that management of point and diffuse sources of microbial pollution is indispensable. Microbial agents may represent the strategic tool that environmental technicians and researchers needed. Microbial tracer studies, using for example Bacillus globigii, can be employed to follow a limited number of inputs at any time [63]. When typical (cultivable) methods are used to trace pollutant movements in surface waters, it is very difficult to attribute the source of pollution to an individual source. Even more when multiple sources are present and different pollutants should be detected. In these cases, it is necessary to define the relative importance for each pollutant and, finally, select appropriate methods of remediation [64]. Simple microbiology is not sufficient to track faecal pollution to individual sources and a long way is still needed to get the expected microbial source tracking (MST) results. 
Presently, the genotyping of F + RNA coliphage and Bacteroidetes spp. is producing few sensible results and these techniques have potential as forensic tools [63].

Finally, as previously described it will not be surprising if in the future we can characterize the individual microbiome and identify individuals based on their microbial community (similarly to what we do today for human DNA and human genetic databases). The potential for such a tool is enormous, particularly by associating perpetuators and victims of sexual offense. Prove for such crimes needs to be obtained in relatively short periods of time (days). Microbial communities tend to stay, interact and evolve in any environment, potentially keeping a trace of evidence for these offenses for longer periods. A personal microbial fingerprint can be the following step of the human microbiome project that was started recently.

\section{CONCLUSIONS}

The most important criteria of microbes to be included on studies by microbial forensics stand until now on the properties that make microorganisms useful as biological weapons [1]. However, this view is in my opinion incomplete and, as described along this min-review, many other microbial features can be used for tracing evidences in space and time. Microbial characteristics, such as accessibility, cultivability, stability in different conditions, ability for dissemination, incubation periods, infectivity, pathogenicity, transmissibility and virulence, are extremely useful for forensic sciences. The availability of (molecular) markers for each microbial feature would largely help researchers working with microbial genetics and for sure will improve confidence on forensic evidences. Additionally, it should not be forgotten that natural conditions can never be possible to mimic at laboratory, probably limiting few microbial analysis and supporting that alternative explanations be regularly explored.

Crime scenes in which evidence are found may provide critical microbial findings that eventually may aid in the conviction or exoneration of individuals. However, the validation process is essential in the development of methods and interpretations that can therefore be used by microbial forensics to generate reliable and defensible results [65]. Law enforcement investigators need to respond quickly to any kind of threat and their prompt answer to a biocrime often rely upon the results produced from the microbial evidence analyses. Severe consequences may come from failing to properly validate a method or misinterpreting the results [65]. The validation process should always define the ability of the procedures, as well as their limitations, the conditions for such result, must recommend quality controls and be periodically verified. Given the still unknown full diversity of the microbial world, additional care should be given to this final step. Extensive research is still needed in this recent and fascinating forensic field but its potential is unlimited.

\section{ACKNOWLEDGMENTS}

The author would like to thank Leonor Gusmão for the critical review of the manuscript. RA was co-financed by the European Social Fund. IPATIMUP is partially supported by Fundação para a Ciência e Tecnologia (FCT), Programa Operacional Ciência e Inovação (POCI) and Programa Operacional do Potencial Humano (POPH - QREN).

\section{REFERENCES}

[1] Budowle, B.; Murch, R.; Chakraborty, R. Microbial forensics: the next forensic challenge. Int. J. Legal Med., 2005, 119, 317-330.

[2] Enserink, M. Taking anthrax's genetic fingerprints. Science, 2001, 294, 1810-1812.

[3] Read, T.D.; Salzberg, S.L.; Pop, M.; Shumway, M.; Umayam, L.; Jiang, L.; Holtzapple, E.; Busch, J.D.; Smith, K.L.; Schupp, J.M.; Solomon. D.; Keim, P.; Fraser, C.M. Comparative genome sequencing for discovery of novel polymorphisms in Bacillus anthracis. Science, 2002, 296, 2028-2033.

[4] Bhattacharjee, Y; Enserink, M. Anthrax investigation. FBI discusses microbial forensics-but key questions remain unanswered. Science, 2008, 321, 1026-1027.

[5] Budowle, B.; Johnson, M.D.; Fraser, C.M.; Leighton, T.J.; Murch, R.S.; Chakraborty, R. Genetic analysis and attribution of microbial forensics evidence. Crit. Rev. Microbiol., 2005, 31, 233-254.

[6] Medini, D.; Serruto, D.; Parkhill, J.; Relman, DA.; Donati, C.; Moxon, R.; Falkow, S.; Rappuoli, R. Microbiology in the postgenomic era. Nat. Rev. Microbiol., 2008, 6, 419-430.

[7] Tringe, S.G.; Zhang, T.; Liu, X.; Yu, Y.; Lee, WH.; Yap, J.; Yao, F.; Suan, ST.; Ing, S.K.; Haynes, M.; Rohwer, F.; Wei, C.L.; Tan, P.; Bristow, J.; Rubin, EM.; Ruan. The airborne metagenome in an indoor urban environment. Y. PLoS One, 2008, 3, e1862.

[8] Fuhrman, J.A. Microbial community structure and its functional implications. Nature, 2009, 459, 193-199.

[9] Montoya, J.P.; Holl, C.M.; Zehr, J.P.; Hansen, A.; Villareal, T.A.; Capone, D.G. High rates of N2 fixation by unicellular diazotrophs in the oligotrophic Pacific Ocean. Nature, 2004, 430, 1027-1032.

[10] Bent, S.J.; Pierson, J.D.; Forney, L.J.; Danovaro, R.; Luna, G.M.; Dell'anno, A.; Pietrangeli, B. Measuring species richness based on microbial community fingerprints: the emperor has no clothes. Appl. Environ. Microbiol., 2007, 73, 2399-2401.

[11] Ranjard, L.; Poly, F.; Lata, J.C.; Mougel, C.; Thioulouse, J.; Nazaret, S. Characterization of bacterial and fungal soil communities by automated ribosomal intergenic spacer analysis fingerprints: biological and methodological variability. Appl. Environ. Microbiol., 2001, 67, 4479-4487.

[12] Grüter, D.; Schmid, B.; Brandl, H. Influence of plant diversity and elevated atmospheric carbon dioxide levels on belowground bacterial diversity. BMC Microbiol., 2006, 6, 68 .

[13] Finlay, B.J. Global dispersal of free-living microbial eukaryote species. Science, 2002, 296, 1061-1063.

[14] Purdy, L.H.; Krupa, S.V.; Dean, J.L. Introduction of sugarcane rust into the Americas and its spread to Florida. Plant Dis., 1985, 69, 689-693.

[15] Hughes, J.B.; Hellmann, J.J.; Ricketts, T.H.; Bohannan, B.J. Counting the uncountable: statistical approaches to estimating microbial diversity. Appl. Environ. Microbiol., 2001, 67, 4399-4406.

[16] Crisp, M.D.; Arroyo, M.T.; Cook, L.G.; Gandolfo, M.A.; Jordan, G.J.; McGlone, M.S.; Weston, P.H.; Westoby, M.; Wilf, P.; Linder, H.P. Phylogenetic biome conservatism on a global scale. Nature, 2009, 458, 754-756.

[17] Condit, R.; Pitman, N.; Leigh, E.G.Jr.; Chave, J.; Terborgh, J.; Foster, R.B.; Núñez, P.; Aguilar, S.; Valencia, R.; Villa, G.; Muller-Landau, H.C.; Losos, E.; Hubbell, S.P. Beta-diversity in tropical forest trees. Science, 2002, 295, 666-669.

[18] Green, J.L.; Holmes, A.J.; Westoby, M.; Oliver, I.; Briscoe, D.; Dangerfield, M.; Gillings, M.; Beattie, A.J. Spatial scaling of microbial eukaryote diversity. Nature, 2004, 432, 747-750.

[19] Rodrigues, D.F.; da C Jesus, E.; Ayala-Del-Río, H.L.; Pellizari, V.H.; Gilichinsky, D.; Sepulveda-Torres, L.; Tiedje, J.M. Biogeography of two cold-adapted genera: Psychrobacter and Exiguobacterium. ISME J, 2009, 3, 658-665.

[20] Papke, R.T.; Ramsing, N.B.; Bateson, M.M.; Ward, D.M. Geographical isolation in hot spring cyanobacteria. Environ. Microbiol., 2003, 5, 650-659.

[21] Whitaker, R.J.; Grogan, D.W.; Taylor, J.W. Geographic barriers isolate endemic populations of hyperthermophilic archaea. Science, 2003, 301, 976-978.

[22] Findlay, R.H.; Yeates, C.; Hullar, M.A.; Stahl, D.A.; Kaplan, L.A. Biome-level biogeography of streambed microbiota. Appl. Environ. Microbiol., 2008, 74, 3014-3021.

[23] Heath, L.E.; Saunders, V.A. Assessing the potential of bacterial DNA profiling for forensic soil comparisons. J. Forensic Sci., 2006, 51, 1062-1068. 
[24] Horswell, J.; Cordiner, S.J.; Maas, E.W.; Martin, T.M.; Sutherland, K.B.; Speir, T.W.; Nogales, B.; Osborn, A.M. Forensic comparison of soils by bacterial community DNA profiling. J. Forensic Sci., 2002, 47, 350-353.

[25] Macdonald, L.M.; Singh, B.K.; Thomas, N.; Brewer, M.J.; Campbell, C.D.; Dawson, L.A. Microbial DNA profiling by multiplex terminal restriction fragment length polymorphism for forensic comparison of soil and the influence of sample condition. J. Appl. Microbiol., 2008, 105, 813-821.

[26] Moreno, L.I.; Mills, D.K.; Entry, J.; Sautter, R.T.; Mathee, K. Microbial metagenome profiling using amplicon length heterogeneity-polymerase chain reaction proves more effective than elemental analysis in discriminating soil specimens. J. Forensic Sci., 2006, $51,1315-1322$.

[27] Nasidze, I.; Li, J.; Quinque, D.; Tang, K.; Stoneking, M. Global diversity in the human salivary microbiome. Genome Res., 2009, 19, 636-643.

[28] Roesch, L.F.; Lorca, G.L.; Casella, G.; Giongo, A.; Naranjo, A.; Pionzio, A.M.; Li, N.; Mai, V.; Wasserfall, C.H.; Schatz, D.; Atkinson, M.A.; Neu, J.; Triplett, E.W. Culture-independent identification of gut bacteria correlated with the onset of diabetes in a rat model. ISME J, 2009, 3, 536-348.

[29] Stackebrandt, E.; Frederiksen, W.; Garrity, G.M.; Grimont, P.A.; Kämpfer, P.; Maiden, M.C.; Nesme, X.; Rosselló-Mora, R.; Swings, J.; Trüper, H.G.; Vauterin, L.; Ward, A.C.; Whitman, W.B. Report of the ad hoc committee for the re-evaluation of the species definition in bacteriology. Int. J. Syst. Evol. Microbiol., 2002, 52, 1043-1047.

[30] McDonald, B.A.; Linde, C. Pathogen population genetics, evolutionary potential, and durable resistance. Annu. Rev. Phytopathol., 2002, 40, 349-379.

[31] Sniegowski, P.D.; Gerrish, P.J.; Lenski, R.E. Evolution of high mutation rates in experimental populations of E. coli. Nature, 1997, 387, 703-705.

[32] Loewe, L.; Textor, V.; Scherer, S. High deleterious genomic mutation rate in stationary phase of Escherichia coli. Science, 2003, $302,1558-1560$.

[33] Finkel, S.E.; Kolter, R. Evolution of microbial diversity during prolonged starvation. Proc. Natl. Acad. Sci. USA, 1999, 96, 40234027.

[34] Fulthorpe, R.R.; Rhodes, A.N.; Tiedje, J.M. High levels of endemicity of 3-chlorobenzoate-degrading soil bacteria. Appl. Environ. Microbiol., 1998, 64, 1620-167.

[35] Cho, J.C.; Tiedje, J.M. Biogeography and degree of endemicity of fluorescent Pseudomonas strains in soil. Appl. Environ. Microbiol., 2000, 66, 5448-5456.

[36] Reno, M.L.; Held, N.L.; Fields, C.J.; Burke, P.V.; Whitaker, R.J. Biogeography of the Sulfolobus islandicus pan-genome. Proc. Natl. Acad. Sci. USA, 2009, 106, 8605-8610.

[37] Strand, M.; Prolla, T.A.; Liskay, R.M.; Petes, T.D. Destabilization of tracts of simple repetitive DNA in yeast by mutations affecting DNA mismatch repair. Nature, 1993, 365, 274-276.

[38] Pâques, F.; Richard, G.F.; Haber, J.E. Expansions and contractions in 36-bp minisatellites by gene conversion in yeast. Genetics, 2001, $158,155-166$.

[39] Araujo, R.; Pina-Vaz, C.; Rodrigues, A.G.; Amorim, A.; Gusmão, L. Simple and highly discriminatory microsatellite-based multiplex PCR for Aspergillus fumigatus strain typing. Clin. Microbiol. Infect., 2009, 15, 260-266.

[40] Balajee, S.A.; de Valk, H.A.; Lasker, B.A.; Meis, J.F.; Klaassen, C.H. Utility of a microsatellite assay for identifying clonally related outbreak isolates of Aspergillus fumigatus. J. Microbiol. Methods., 2008, 73, 252-256.

[41] Verstrepen, K.J.; Reynolds, T.B.; Fink, G.R. Origins of variation in the fungal cell surface. Nat. Rev. Microbiol., 2004, 2, 533-540.

[42] Levdansky, E.; Sharon, H.; Osherov, N. Coding fungal tandem repeats as generators of fungal diversity. Fungal Biol. Rev., 2008, 22, 85-96.

[43] Coates, B.S.; Hellmich, R.L.; Lewis, L.C. Allelic variation of a Beauveria bassiana (Ascomycota: Hypocreales) minisatellite is independent of host range and geographic origin. Genome, 2002, 45, 125-132.

[44] Keim, P.; Pearson, T.; Okinaka, R. Microbial forensics: DNA fingerprinting of Bacillus anthracis (anthrax). Anal. Chem., 2008, 80, 4791-4799.
[45] Kreuzer-Martin, H.W.; Jarman, K.H. Stable isotope ratios and forensic analysis of microorganisms. Appl. Environ. Microbiol., 2007, 73, 3896-3908.

[46] Kreuzer-Martin, H.W.; Lott, M.J.; Dorigan, J.; Ehleringer, J.R. Microbe forensics: oxygen and hydrogen stable isotope ratios in Bacillus subtilis cells and spores. Proc. Natl. Acad. Sci. USA, 2003 100, 815-819.

[47] Budowle, B. Genetics and attribution issues that confront the microbial forensics field. Forensic Sci. Int., 2004, 146, S185-S188.

[48] Budowle, B.; Schutzer, S.E.; Ascher, M.S.; Atlas, R.M.; Burans, J.P.; Chakraborty, R.; Dunn, J.J.; Fraser, C.M.; Franz, D.R.; Leighton, T.J.; Morse, S.A.; Murch, R.S.; Ravel, J.; Rock, D.L.; Slezak, T.R.; Velsko, S.P.; Walsh, A.C.; Walters, R.A. Toward a system of microbial forensics: from sample collection to interpretation of evidence. Appl. Environ. Microbiol., 2005, 71, 2209-2213.

[49] Budowle, B.; Harmon, R. HIV legal precedent useful for microbial forensics. Croat. Med. J., 2005, 46, 514-521.

[50] Jackson, P.J.; Hugh-Jones, M.E.; Adair, D.M.; Green, G.; Hill, K.K.; Kuske, C.R.; Grinberg, L.M.; Abramova, F.A.; Keim, P. PCR analysis of tissue samples from the 1979 Sverdlovsk anthrax victims: the presence of multiple Bacillus anthracis strains in different victims. Proc. Natl. Acad. Sci. USA, 1998, 95, 1224-1229.

[51] Metzker, ML.; Mindell, D.P.; Liu, XM.; Ptak, R.G.; Gibbs, R.A.; Hillis, D.M. Molecular evidence of HIV-1 transmission in a criminal case. Proc. Natl. Acad. Sci. USA, 2002, 99, 14292-14297.

[52] Ou, CY.; Ciesielski, C.A.; Myers, G.; Bandea, C.I.; Luo, C.C.; Korber, B.T.; Mullins, J.I.; Schochetman, G.; Berkelman, R.L.; Economou, A.N.; Witte, J.J.; Furman, L.J.; Satten, G.A.; Maclnnes, K.A.; Curran, J.W.; Jaffe, H.W.; Laboratory Investigation Group; Epidemiologic Investigation Group. Molecular epidemiology of HIV transmission in a dental practice. Science, 1992, 256, 11651171.

[53] González-Candelas, F.; Bracho, M.A.; Moya, A. Molecular epidemiology and forensic genetics: application to a hepatitis $\mathrm{C}$ virus transmission event at a hemodialysis unit. J. Infect. Dis., 2003, 187, 352-358.

[54] Kolavic, S.A.; Kimura, A.; Simons, S.L.; Slutsker, L.; Barth, S.; Haley, C.E. An outbreak of Shigella dysenteriae type 2 among laboratory workers due to intentional food contamination. JAMA, 1997, 278, 396-398.

[55] Van Ert, M.N.; Easterday, W.R.; Simonson, T.S.; U'Ren, J.M.; Pearson, T.; Kenefic, L.J.; Busch, J.D.; Huynh, L.Y.; Dukerich, M.; Trim, C.B.; Beaudry, J.; Welty-Bernard, A.; Read, T.; Fraser, C.M.; Ravel, J.; Keim, P. Strain-specific single-nucleotide polymorphism assays for the Bacillus anthracis Ames strain. J. Clin. Microbiol., 2007, 45, 47-53.

[56] Van Ert, M.N.; Easterday, W.R.; Huynh, L.Y.; Okinaka, R.T.; Hugh-Jones, M.E.; Ravel, J.; Zanecki, S.R.; Pearson, T.; Simonson, T.S.; U'Ren, J.M.; Kachur, S.M.; Leadem-Dougherty, R.R.; Rhoton, S.D.; Zinser, G.; Farlow, J.; Coker, P.R.; Smith, K.L.; Wang, B.; Kenefic, L.J.; Fraser-Liggett, C.M.; Wagner, D.M.; Keim, P. Global genetic population structure of Bacillus anthracis. PLoS One, 2007, 2, e461.

[57] Cummings, C.A.; Relman, D.A. Genomics and microbiology. Microbial forensics--"cross-examining pathogens". Science, 2002 296, 1976-1979.

[58] Lanciotti, R.S.; Roehrig, J.T.; Deubel, V.; Smith, J.; Parker, M.; Steele, K.; Crise, B.; Volpe, K.E.; Crabtree, M.B.; Scherret, J.H.; Hall, R.A.; MacKenzie, J.S.; Cropp, C.B.; Panigrahy, B.; Ostlund, E.; Schmitt, B.; Malkinson, M.; Banet, C.; Weissman, J.; Komar, N.; Savage, H.M.; Stone, W.; McNamara, T.; Gubler, D.J. Origin of the West Nile virus responsible for an outbreak of encephalitis in the northeastern United States. Science, 1999, 286, 2333-2337.

[59] Fletcher, J.; Bender, C.; Budowle, B.; Cobb, W.T.; Gold, S.E.; Ishimaru, C.A.; Luster, D.; Melcher, U.; Murch, R.; Scherm, H.; Seem, R.C.; Sherwood, J.L.; Sobral, B.W.; Tolin, S.A. Plant pathogen forensics: capabilities, needs, and recommendations. Microbiol. Mol. Biol. Rev., 2006, 70, 450-471.

[60] Herwaldt, B.L.; Ackers, M.L. An outbreak in 1996 of cyclosporiasis associated with imported raspberries. The Cyclospora Working Group. N. Engl. J. Med., 1997, 336, 1548-1556.

[61] Herwaldt, B.L.; Beach, M.J. The return of Cyclospora in 1997: another outbreak of cyclosporiasis in North America associated 
with imported raspberries. Cyclospora Working Group. Ann. Intern. Med., 1999, 130, 210-220.

[62] Carter, D.O.; Yellowlees, D.; Tibbett, M. Cadaver decomposition in terrestrial ecosystems. Naturwissenschaften, 2007, 94, 12-24.

[63] Stapleton, C.M.; Wyer, M.D.; Kay, D.; Crowther, J.; McDonald, AT.; Walters, M.; Gawler, A.; Hindle, T. Microbial source tracking: a forensic technique for microbial source identification? J. Environ. Monit., 2007, 9, 427-439.
[64] Witty, M.; Nickels, J.; Lisa, J.; Tiedemann, J. Ecology, DNA, and the Future of microbial source tracking. Water Air Soil Pollut., 2009, 201, 219-232.

[65] Budowle, B.; Schutzer, S.E.; Morse, S.A.; Martinez, K.F.; Chakraborty, R.; Marrone, B.L.; Messenger, S.L.; Murch, R.S.; Jackson, P.J.; Williamson, P.; Harmon, R.; Velsko, S.P. Criteria for validation of methods in microbial forensics. Appl. Environ. Microbiol., 2008, 74, 5599-5607.

(C) Ricardo Araujo; Licensee Bentham Open.

This is an open access article licensed under the terms of the Creative Commons Attribution Non-Commercial License (http://creativecommons.org/licenses/by-nc/3.0/) which permits unrestricted, non-commercial use, distribution and reproduction in any medium, provided the work is properly cited. 